\title{
When to start antiretroviral therapy: asking the right question
}

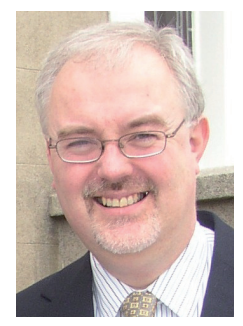

\author{
"A striking feature of the evolution of guidelines \\ over the last 15 years has been the gradual shift to \\ earlier and earlier initiation of therapy."
}

William G Powderly

UCD School of Medicine \& Medical Sciences, Health Sciences Centre, University College Dublin, Belfield Dublin 4, Ireland = Tel.: +353 17166609 m Fax: +353 17166585 m bill.powderly@ucd.ie

One of the strengths of HIV medicine is the extent of the evidence base for the management of patients. This is particularly true when it is applied to antiretroviral therapy (ART). A strong example of this evidence base is the robustness of guidelines for ART that have been published to help guide practitioners and patients in the latest perspectives on appropriate management. A striking feature of the evolution of guidelines over the last 15 years has been the gradual shift to earlier and earlier initiation of therapy. The most recent iterations of the US Public Health Service [101] and International AIDS Society-USA (IAS-USA) guidelines [1] now recommend therapy for all patients with $\mathrm{CD}^{+}$T-cell counts $<500$ cells $/ \mathrm{mm}^{3}$ and recommend strong consideration of therapy above that threshold. European guidelines [2,3] are still more conservative in terms of higher $\mathrm{CD} 4{ }^{+}$counts but the trend in these guidelines has also been to recommend earlier initiation of treatment.

From one perspective, the strength of the evidence base for these more expanded guidelines is weak. Prospective clinical trials have not definitely proved that earlier initiation of ART at higher CD4 $4^{+}$counts is associated with clinical benefit when compared with waiting until the $\mathrm{CD} 4{ }^{+}$counts reach a lower threshold. Guidelines are therefore driven more by expert opinion using subset analyses of some clinical trials and data from observational cohorts. Indeed, given that cohort data have generally examined the question of starting below a $\mathrm{CD} 4^{+}$count of 350 cells $/ \mathrm{mm}^{3}$, with some observational data reporting on treatment at $\mathrm{CD} 4{ }^{+}$counts between 350 and 500 cells $/ \mathrm{mm}^{3}$, one can argue that the recommendations to start at higher $\mathrm{CD} 4{ }^{+}$counts are purely based on experts extrapolating from the available evidence and assuming the benefits of initiating early treatment.

For most people familiar with the field and the debate, the pros of starting earlier and the pros of deferring are familiar territory $[4,5]$. Rather than arguing these further, is it worth asking whether we are becoming too focused on a debate that in the greater scheme of things is rather less important than the attention it receives?

First, we are still in a situation with HIV infection where this debate is moot and meaningless for many patients. Too many HIVinfected individuals still present late [6] - with more advanced disease and at a point in their immunodeficiency where therapy is indicated in every guideline.

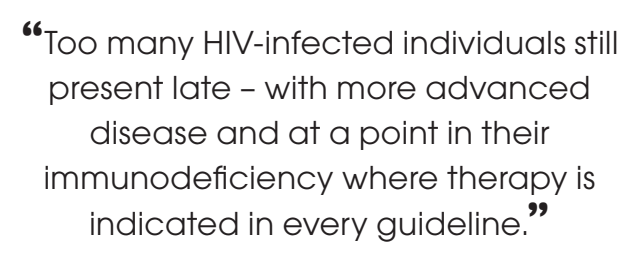

Second, the vast majority of patients will require therapy at some point. Well over 90\% of HIV-infected patients will experience progression of immune deficiency. Deferral of therapy does not mean avoidance of therapy for the majority of individuals. At the moment, we are looking at a lifetime of ART - there is presently no realistic prospect of cure, viral rebound occurs on cessation of therapy, and stopping ART appears to be a bad idea. Thus, is delaying the initiation of treatment for 1 year or 2 such a 'big deal' over the 40-50 years of total treatment that may well be required?

Third, a CD4 ${ }^{+}$T-cell count of 500 cells $/ \mathrm{mm}^{3}$ has no more biologic significance as a threshold than 350 or even 200 cells $/ \mathrm{mm}^{3}$. As a single measurement, it is an indicator of where in the natural history of HIV infection an individual resides, but alone it cannot predict the degree of

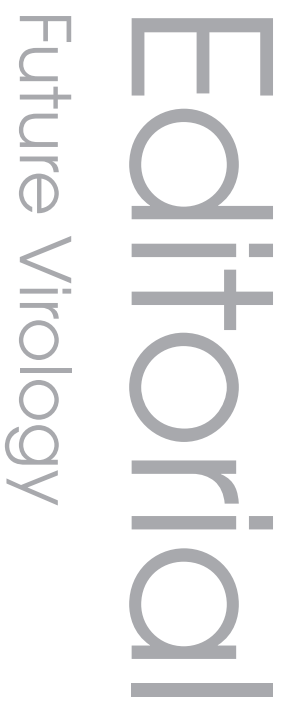

\section{Keywords}

- antiretroviral therapy = guidelines $=$ HIV-AIDS - HIV progression

\section{future medicine $_{\text {msg }}$}


prior or future damage from viral replication. $\mathrm{CD} 4{ }^{+}$counts serve as useful cut-offs in epidemiologic studies to allow for categorization into groups, but are less useful in determining whether the pathogenic effect of HIV infection in an individual warrants intervention.

\section{'Deferral of therapy does not mean avoidance of therapy for the majority of individuals."}

Perhaps the debate should be re-framed. Instead of the question being 'when should I start therapy?', would patients be better served with the discussion being refocused to ask 'in which patients should treatment not be started?' In other words, should we consider that the default position should be to start ART in all patients - unless there is cogent reason not to start therapy?

Why might this be more logical? Importantly, it emphasizes that this is a chronic viral infection with ongoing high-level viral replication that has a persistent effect, particularly on the immune system, leading to immune dysfunction that also includes immune activation. This would remind everyone that this viral replication has pathogenic consequences that are not benign and may lead to other noninfectious, nonimmunologic disease manifestations as well as progressive immune deficiency. Are there many other infections for which we make a diagnosis, recognize that there is active damage from a replicating organism and decide that we will wait until there is more damage and a greater pathologic effect before intervening? This may have been a valid proposition (although, on the face of it, still illogical) when there were serious misgivings about the toxicity of treatment, but surely that is less compelling with the current era of effective and 'relatively' safe treatments.

A change in philosophy may not have much of an immediate effect for many patients. I am not advocating immediate therapy without thought. Indeed, I would still favor referral to clinical trials evaluating this approach if the patient was willing to accept randomization [7] Initiating ART is not a trivial consideration and some side effects are inevitable. There are some patients with higher $\mathrm{CD} 4{ }^{+}$counts who will not have a rapid progression - typically, those with low viral loads. Given that the pathogenic effect correlates in many cases with viral load, it would be reasonable to determine the pace of the illness and the degree of immunosuppression over time in such patients. Other biomarkers may ultimately prove useful in this context $[8,9]$. Furthermore, patients will need education, and time to come to terms with the need for life-long therapy - identifying patients in the earlier phases of infection does allow for such a preparation, which may increase adherence and decrease the risk of treatment failure with the attendant risk of acquisition (and possible transmission) of resistant virus.

"... deferring treatment should not translate to deferring decisions."

However, the most important effect of reframing the question is on the attitude of physicians and patients to therapy. Making the decision one of not treating rather than treating (which I believe is more rational given the inevitability of treatment in the majority of patients) should lead to a more proactive approach to making the correct choices for individual patients. It should start the process of an active engaged decision rather than the mind-set of thinking about it later. In other words, deferring treatment should not translate to deferring decisions.

\section{Financial \& competing interests disclosure \\ WG Powderly has served on data and safety monitoring boards for Tibotec and has consulted for Abbott and Gilead. The author has no other relevant affiliations or financial involvement with any organization or entity with a financial interest in or financial conflict with the subject matter or materials discussed in the manuscript apart from those disclosed. \\ No writing assistance was utilized in the production of this manuscript.}

Antiretroviral Therapy. HIV Med. 9 , 563-608 (2008).

4. Wilkin TJ, Gulick RM: When to start antiretroviral therapy? Clin. Infect. Dis. 47, 1580-1586 (2008) Treatment of HIV-1-Infected Adults with
5. Lundgren JD, Phillips AN, Neaton J: Uncertainty as to whether the use of antiretroviral therapy for persons recently
3. Gazzard BG, Anderson J, Babiker A et al.: British HIV Association Guidelines for the Executive Committee: European AIDS Clinical Society (EACS) guidelines for the clinical management and treatment of HIV-infected adults. HIV Med. 9, 65-71 (2008).

infection: 2010 recommendations of the International AIDS Society-USA panel. JAMA 304, 321-333 (2010). 
infected with HIV has a favorable risk-tobenefit ratio. Clin. Infect. Dis. 48, 1162-1163 (2009).

6. Antinori A, Coenen T, Costagiola D et al.: Late presentation of HIV infection: a consensus definition. HIV Med. 12, 61-64 (2011).

7. Phillips AN, Emery S: Predicting the potential benefits of early initiation of ART: time to do a trial to find out. Curr. Opin. HIV AIDS 4, 165-166 (2009).
8. Justice AC, McGinnis KA, Skanderson M et al:: Towards a combined prognostic index for survival in HIV infection: the role of 'non-HIV' biomarkers. HIV Med. 11, 143-151 (2010).

9. Skoutelis A, Goetz MB, Phillips AN; for the INSIGHT Strategies for Management of Antiretroviral Therapy (SMART) Study Group: Activation and coagulation biomarkers are independent predictors of the development of opportunistic disease in patients with HIV infection. J. Infect. Dis. 200, 973-983 (2009).

\section{Website}

101. Panel on Antiretroviral Guidelines for Adults and Adolescents. Guidelines for the use of antiretroviral agents in HIV-1-infected adults and adolescents. Department of Health and Human Services. 10 January, $1-166$ (2011)

www.aidsinfo.nih.gov/ContentFiles/ AdultandAdolescentGL.pdf

(Accessed 21 February 2011) 